

\title{
Roland Barthes e a fotografia Roland Barthes and Photography
}

\author{
Rodrigo Fontanari*
}

\begin{abstract}
Resumo: O presente artigo constitui-se numa resenha e numa pequena exegese de alguns dos mais notáveis textos de comentadores internacionais, notadamente aqueles ainda não traduzidos em língua portuguesa, a se consagrar ao derradeiro livro de Roland Barthes publicado em vida do autor: A câmara clara. O que aqui se propõe é oferecer subsídios para uma melhor elucidação dessa importante obra, que, a trinta anos de seu surgimento, continua pouco estudada, sendo assim desperdiçada sua enorme contribuição às ciências da comunicação e, sobretudo, às reflexões em torno do papel da imagem fotográfica no mundo contemporâneo. Sustentamos a hipótese de que, sendo um semioclasta, mais que um iconoclasta, Barthes estava em melhor posição para ler e entender imagens.
\end{abstract}

Palavras-chave: Roland Barthes; fotografia; semiótica; imagem.

\begin{abstract}
This is a review article and a short exegesis from one of the most important texts of international commentators, especially those not yet translated into Portuguese, that we may consider the last work in Barthes's life, Camara Lucida. What is proposed here is to offer subsidies to elucidate this important work, which, thirty years after its formation, it hasn't been so much studied, and its huge contribution to science communication got lost, and especially the reflections on the role of photographic image in the contemporary world. It's possible to make some hypothesis that, being a semioclasta, rather than an iconoclast, Barthes was in a better position to read and understand images.
\end{abstract}

Keywords: Roland Barthes; photography; semiotics; image.

* Graduado em Comunicação Social pela Universidade de Ribeirão Preto (2005). Mestre pela PUC/SP - Pontifícia Universidade Católica de São Paulo (2008). Doutorando em Comunicação e Semiótica na mesma instituição. E-mail: rodrigo-fontanari@hotmail.com 


\section{Introdução}

O objetivo desse artigo é apresentar uma resenha e exegese dos principais textos de comentadores internacionais, de difícil acesso, atualmente, no Brasil e, sobretudo, daqueles textos ainda não traduzidos em língua portuguesa que se lançaram na tentativa de compreender a última obra publicada em vida de Roland Barthes, $A$ câmara clara.

Cabe, nesse momento, uma pequena e breve apresentação do autor e sua obra. Roland Barthes (1915-1980) um dos maiores expoentes da intelligentsia francesa do século XX, influenciado pelo pensamento do linguista Ferdinand Saussure, pertenceu à escola estruturalista, foi um intelectual irrequieto, o que dificulta qualquer tentativa de chancelá-lo sob um título. Como ele mesmo se apresenta em sua aula inaugural no Collège de France, "um sujeito incerto, no qual cada atributo é, de certo modo, imediatamente combatido por seu contrário”. (BARTHES, 2002, p.429).

Podemos considerar que ele foi escritor, crítico literário, semiólogo, e sobretudo, um filósofo. A câmara clara constitui uma “meditação" a respeito da imagem fotográfica, como de saída já sugere o próprio subtítulo da obra “nota sobre fotografia”. Seus 48 fragmentos escritos em 48 dias (15 de abril - 3 junho de 1979) sugerem mesmo se tratar de um diário de Barthes que reflete sobre a imagem e a morte e, notadamente, sobre um luto recente, a perda de sua mãe, Henriette Barthes (1893-1977). (SAMAIN, 1998, p.128). A Fotografia do Jardim de Inverno, em que figura sua mãe, desempenha um papel importante nesse livro. É do que advém dessa imagem, que Barthes busca interrogar a essência da fotografia.

O que nos revela, na atualidade, o conjunto da obra barthesiana é que, apesar de seus inúmeros deslocamentos, há uma coesão interna de seus escritos. Barthes busca, no decorrer de toda sua obra, as brechas do "grau zero" por meio da evocação da abstinência de imagens, 
suspensão, silêncio e vazio. Ao contrário dos iconoclastas, a intenção das brechas do "grau zero" não pretendia destruir as imagens, mas descolá-las e colocá-las à distância para melhor perscrutá-las. Os escritos barthesianos ensinam que o caminho para subverter a imagem e corromper a linguagem é a estética e a literatura.

\section{Uma pequena história da fotografia?}

Na busca de levantamento do estado da arte a respeito dos escritos sobre fotografia de Roland Barthes, deparamo-nos, recentemente, com dois textos instigantes, ambos publicados na revista Comunicação \& Linguagem da Universidade Nova de Lisboa, num dossiê intitulado Fotografia(s): uma abordagem multidisciplinar. (MEDEIROS, 2008). Um deles é A câmara clara: outra pequena história da fotografia, de Geoffrey Batchen, professor da City University of New York, um dos maiores especialistas em teoria e historiografia da fotografia. O autor questiona as muitas histórias da fotografia de que dispomos hoje, vendo faltar nelas tudo aquilo que, por outro lado, encontra em Barthes. O último dos escritos barthesianos é, no seu entender, outra Pequena história da fotografia, digna do importante texto de Walter Benjamin, escrito em 1931, quase 50 anos antes do volume barthesiano.

Batchen (2008, p.14) nota que o discurso mais insistente em torno de Acâmara clara é o de que a obra seria a pior coisa que teria acontecido ao discurso fotográfico, uma vez que o livro "parece abandonar o compromisso inicial de Barthes com a análise política das imagens em favor de um hedonismo textual”. De fato, como se sabe, o que Barthes buscava era a essência da fotografia, que permitiria distingui-la de todas as demais imagens. Batchen diz ainda que o livro desenvolve uma história da fotografia, muito mais do que qualquer teoria crítica, e a maneira como põe em descrédito a maioria das discussões a respeito do par opositivo 
studium e punctum, assim como do subtema do livro, a relação da fotografia e da morte. Estas abordagens típicas da obra desviam o olhar da possibilidade de encontrar, justamente, uma outra pequena história da fotografia, nota ele.

Desde as primeiras páginas, Batchen (2008) busca comparar estruturalmente A câmara clara ao ensaio de Benjamin, começando por mostrar que ambos ilustram a sua história com fotografias relativamente banais, que, no entanto, são capazes de disparar leituras poéticas, como se também Benjamin procurasse apreender o efeito de punctum. Apesar das inúmeras correspondências e similitudes - acrescenta ele-Barthes não faz nenhuma referência a Benjamin, nem em sua biografia nem em suas habituais notas marginais. $\mathrm{O}$ fato é tão mais intrigante quanto tudo aponta que, na edição de 1977 da revista Nouvel Observateur Photo, da qual Roland Barthes retirou a maioria das fotografias que ilustraram $A$ câmara clara, constava uma versão francesa do célebre ensaio benjaminiano. (BATCHEN, 2008, p.17).

O que se nota, a partir da leitura de A câmara clara, é que a “Pequena história da fotografia” implode o tom objetivo e se entrega a uma forma narrativa em primeira pessoa que enuncia a experiência do sujeito diante da fotografia e de seu laço traumático com o passado. O mais inusitado é que Barthes escolhe fotografias públicas para falar de algo bem íntimo, do que há de mais traumático na experiência fotográfica: o "isso existiu”. Essas fotos parecem importar menos como corpus de uma pesquisa e mais como pretexto (pré-texto) para o texto: uma escritura da experiência do sujeito diante da imagem. Como escreve Batchen (2008, p.23):

A História continua a ser um lugar poderoso para esse trabalho, como fica evidente na forma como Barthes leva a cabo a representação da sua pequena história da fotografia. Abandonando a narrativa linear e cronológica, as afirmações ilusórias da compreensibilidade, e os valores hierárquicos da maioria dos estudos em fotografia, esta é uma história guiada por uma única pergunta por responder: o que é a fotografia? Ao inserir está ansiedade ontológica no seio da sua narrativa, Barthes não 
estabelece previamente nenhuma direção para essa narrativa. Ao invés, os leitores são conduzidos numa demanda - com um pouco de ruminação filosófica, um pouco de história social, um pouco de cultura visual, um pouco de romance de detetives - que fala tanto acerca deles próprios (acerca da consciência) como da fotografia.

Barthes (2008, p.22) parece interessado em explorar a possibilidade de inventar uma forma vanguardista de história, e não em fornecer, uma vez mais, uma história das imagens vanguardistas. Em qualquer dos casos, o objetivo do seu livro é descobrir a natureza da experiência oferecida por qualquer fotografia. Em suma, a abordagem é da fotografia e não das fotografias.

Batchen também sustenta a ideia de que a essência da fotografia é a de ser um signo indiciário, o que a distingue de outros sistemas de representação. Como ele escreve: "A noção perciana de semiose indiciária anula qualquer distinção clara entre um referente e as associações psicológicas a ele atribuídas por um observador.” (BATCHEN, 2008, p.19).

No entanto, se A câmara clara pode ser lida como uma outra "Pequena história da fotografia”, isso se deve também, segundo Batchen, ao que ela significa em seu momento. De fato, quando foi escrito, no final de 1979, a fotografia já estava institucionalizada como objeto histórico e prática profissional, e o livro de Barthes soou como último testemunho que "associam intimamente a fotografia à história, e as suas pequenas histórias como a sua própria experiência de fotografias reais, como se o destino de uma dependesse da forma da outra”. (BATCHEN, 2008, p.23).

Em seu Le pas philosophique de Roland Barthes, Jean-Claude Milner parece ir ao encontro a Batchen. Para Milner, cada palavra, cada alusão de Barthes deve ser levada a sério. A câmara clara é o momento em que Barthes se solta do mastro do barco e se entrega ao canto das sereias, metáfora que referenda "O canto da sereia” em $O$ livro por vir de Maurice Blanchot.

Nesta perspectiva, Barthes acaba por condenar o pensamento de Walter Benjamin "na esteira de pensamento de Benjamin, a 
condenação é plena e inteira”. (MILNER, 2003, p.72). Para esse autor não há nenhuma referência clara ao ensaio de Benjamin. A única referência - e, de maneira explícita - aparece em uma entrevista concedida por Barthes em 1977 e publicada em 1980 em que ele afirma que, entre os raros textos dignos de nota está o de Benjamin. Porém, nada habilita a constatar que ele referendava Pequena história da fotografia ou A obra de arte na era da reprodutibilidade técnica. O seu julgamento a respeito do texto de Benjamin é de que ele é "bom por ser premonitório”. (MILNER, 2003, p.72). Estas palavras de Barthes parecem, enfim, sugerir que o texto benjaminiano tem apenas valor histórico.

De outro ponto de vista, Barthes inverte a tese. Segundo Benjamin, o anjo da história caminha para trás no futuro, nas vidas por vir, mais do que na morte. Já o caminho escolhido por Barthes para falar de fotografia foi de remontar os escombros do passado: "Impulsionado pelo progresso, ele contempla os escombros de um passado.” (MILNER, 2003, p.72).

Elencando elementos que afastam Benjamin de Barthes, JeanClaude Milner aponta que Barthes diz não à história - uma invenção moderna tal como a fotografia - para dizer sim à fotografia como arte técnica que congela o tempo, faz do instante algo infinito: reproduz mecanicamente algo que não poderá mais se reproduzir existencialmente.

Este posicionamento barthesiano diante da fotografia vem ao encontro ao pensamento Benjamin desenvolvido em outro ensaio célebre, intitulado A obra de arte na era da reprodutibilidade técnica, pois para Barthes o que se inaugura na era da reprodutibilidade técnica - notadamente para o mundo da fotografia - nada altera em relação ao que era considerado como obra de arte até então, visto que, “o que se fotografa não deixa de se tornar o que é - único”. (MILNER, 2003, p.73). O que se fotografa se torna irrepetível, embora reproduzível ao infinito. Para Barthes a fotografia parece não perder o conceito benjaminiano de “aura”, pois, ela sempre - por mais reproduzida que a fotografia vem a ser - será o registro de um instante único. Eis-aí, o escândalo barthesiano de A câmara clara. 


\section{A imagem e a morte / a fotografia e o duplo}

O outro texto recolhido nesta revista é $A$ fotografia, a modernidade e seu segredo. Antes e depois de Barthes, de Margarida Medeiros, professora do Departamento de Ciência da Comunicação da Universidade Nova de Lisboa. Ao elaborar um fio condutor da passagem progressista da fotografia que emerge centrada no espanto pela revolução tecnológica do instante congelado de que nos fala a fotografia, a autora se dedica a demonstrar uma "concepção mais necrófila, que vê na fotografia não o espelho do progresso, mas da dissolução do Ser, e que fala insistentemente da fotografia como um dispositivo mortífero". (MEDEIROS, 2008, p.27). No decorrer de seu artigo, a autora demonstra que a morte esteve mais ou menos presente na história da fotografia. Nem mesmo autores contemporâneos, tal como Philippe Dubois, em $O$ ato fotográfico, conseguiu retirar a fotografia desse lamaçal da morte, ao situar a ato fotográfico entre o mito de Narciso e de Medusa, a Górgona de cabelos em forma de serpente que petrifica de horror que ousa mirá-la.

Nesse artigo, Margarida Medeiros elenca um conjunto de textos célebres a respeito da teoria crítica da fotografia para situar o papel da imagem fotográfica na cultura moderna, sinalizando que esses textos não nos falam simplesmente de uma evidência de pensamento a respeito da fotografia, mas também de uma experiência dos traumas vivenciados.

$\mathrm{O}$ percurso textual escolhido pela autora parte das primeiras utilizações da fotografia no século XIX, quando então se fotografavam as pessoas em seus leitos de morte. A morte era o vetor da atividade fotográfica: ter um registro dos seus entes queridos antes ou mesmo depois, já morto. Até mesmo durante o sonho positivista e cientificista naturalista - de fotografar a retina do morto para registrar a última imagem vista pelos olhos do mesmo - que foi de 1860 até o início do século XX. A ideia de morte, ou pelo menos do cadáver, está de certa forma impregnada nos primeiros daguerreótipos em que os retratados permaneciam longos períodos de exposição de maneira rígida, atribuindo-lhe uma certa face 
nítida, mas macabra e estranha (mortuária), pois para ser retratado era necessário se fazer morto.

A autora aponta, a partir da segunda meta de do século XX, um crescente estranhamento do dispositivo fotográfico, que culminou na construção de uma visão tétrica desse aparato técnico de fabricação de imagens. São os textos de Susan Sontag, Sobre fotografia, e de Roland Barthes, A câmara clara, que coroam uma reflexão apurada para uma interpretação do dispositivo fotográfico como um mecanismo que evoca uma reflexão "sobre a fugacidade da experiência, sobre a morte" (MEDEIROS, 2008, p.28), ao notarem claramente a relação da prática fotográfica e da fotografia com a morte. Barthes considera talvez a fotografia uma imagem que produz a morte, enquanto Sontag discorre sobre o significado da fotografia na cultura contemporânea, ressaltando os aspectos como: o aparelho fotográfico como arma, a prática fotográfica como caçada. Remete constantemente a essa idéia de imagem secular, intimamente relacionada à passagem do tempo e ao "fetichismo da mercadoria”. (MEDEIROS, 2008, p.39). Neste sentido, como coloca Miguel Frade, quando se põe a pensar um outro tempo da fotografia: do pioneirismo e do espanto que representava ainda ao olhar o processo para obter uma fotografia:

O que equivale a dizer que os espantos, hoje, são fundamentalmente outros: porque a imagem fotográfica foi-se tornando incapaz, ao longo da sua história, de espantar quem quer que seja pela sua simples natureza foto-gráfica. [...] A imagem fotográfica tornou-se habitual, banal, natural: pensamos saber, ou melhor, esquecemo-nos de que não sabemos exatamente o que ela representa o que ela implica o que ela faz e não faz, e esquecemonos, sobretudo de que ela existe já que, como técnica disponível para gerir as aparências, que por ela se tornam elas mesmas disponíveis, o dispositivo liga-se assim ao domínio da mundaneidade banal [...]. (FRADE, 1992, p.13).

Essa concepção necrofilizante projetou e se amalgamou sobre a história da fotografia como se desde o início a fotografia tivesse sido 
concebida como um dispositivo de morte. “Toda a sua história é olhada e envolvida num cenário tétrico, não porque isso seja feito explicitamente, mas porque é visível na forma como a teoria e a história da fotografia se relacionam com o passado desta.” (MEDEIROS, 2008, p.33).

Nesse sentido, como bem sinaliza a autora, a crítica contemporânea da imagem tem citado incessantemente o texto de Sigmund Freud, Das Unheimliche (O sinistro), texto datado de 1919. Para mostrar a ideia de duplicar um objeto, um personagem acena com a possibilidade de negar a finitude em detrimento de assegurar a sua continuidade, assim como seus desdobramentos amplamente experimentados na literatura. Da ideia primitiva da imagem duplicada do “eu”, essa cópia fiel que surge da projeção do corpo sobre uma superfície - qualquer seja ela o espelho ou muro - traz consigo o conceito freudiano de sinistro ou estranho. Pois é a reaparição de algo que por muito tempo era conhecido mas que, por algum motivo, foi recalcado, e que ao vir à tona se tornou pavoroso. Esse sentimento para Freud deve-se ao retorno do recalcado, que está relacionado principalmente à castração, à compulsão, à repetição e a medos ancestrais parcialmente superados.

As investigações freudianas a respeito do conceito de sinistro partem, de um lado, de uma vertente etimológica, que nos interessa particularmente nesse momento, da palavra alemã empregada por Freud para designar o conceito de sinistro - Unheimliche -, palavra que encerra os sentidos opostos de algo familiar que é, ao mesmo tempo, vivido com estranheza. E de outro, uma análise das obras literárias que tematizaram a questão do duplo e que provocam no leitor a sensação de Unheimliche. Tal inquietante estranheza pode ser provocada pela imobilidade de um ser ou vice e versa. Nas palavras de Cesarotto (1996, p.127): “quando o inacreditável aparece como real [...] um símbolo assume o lugar e a importância do que é simbolizado, o sinistro vem a lume”.

Como lembra ainda Cesarotto (1996), todos os nossos sentidos podem vir a ser atingidos pela sensação de estranheza (Unheimliche). 
Porém, ele ressalta que a visão - o campo escópico - é o mais privilegiado dos sentidos corporais a levar esta para acesso à essa questão: a visão nos possibilita a sensação de certeza (realidade das coisas: aquilo que vejo realmente existe): “A apreensão do real por meio dos olhos permite ao sujeito posicionar perante o mundo externo que, por esta operação, é interiorizada e metabolizada pelo eu.” (CESAROTTO, 1996, p.134).

O pensamento barthesiano da fotografia rebate o de Freud: o que é estranho, de grande inquietude (sinistro), parece querer ser negado através de um processo de repetição compulsiva que busca a banalização/normalização, tornando-o “familiar”. Toda a concepção barthesiana de fotografia está construída a partir da noção semiótica de índice na medida em que para ela a fotografia traz sempre consigo seu referente, numa conexão profunda. Tal é a impregnação dessa concepção indiciária que atribuem a essas imagens técnicas o papel de “almas de um outro mundo” que regressam. O projeto inicial de Barthes de chegar à essência da fotografia fracassa na medida em que a fotografia revela algo que é da ordem do recalcado, aquilo que é demasiadamente obsceno e, por isso, não é verbalizável. Nas palavras de Frade (1992, p.206):

A fotografia é hoje objeto de uma outro mal-estar, também este na civilização, à medida que o seu lugar presente se reconfigura sob a pressão constante de um futuro que começa a eclodir já hoje, como a explosão das imagens que tudo mimam sem que nada se refiram: face ao que se avizinha, talvez não seja de menor importância assinalar de que modo a fotografia, apesar de poder ser absolutamente irreal, não deixa de exigir uma contacto com a superfície do mundo para se fazer. É nesse sentido que ela pode ser louca, quando o seu realismo absoluto e original começar a surpreender-nos em demasia apenas por poder fazer 'regressar à consciência’ [...] a própria marca do tempo.

O que se rompe no horizonte da busca para pensar a fotografia é a pergunta sobre qual o caminho possível e interessante para compreender 
os efeitos comportamentais que a fotografia provoca, quando se esforça na denegação de uma "inquietante estranheza."

\section{Alguns toques de sutileza fotográfica barthesiana}

Na mesma perspectiva de leitura psicanalítica de A câmara clara, Serge Tisseron, psiquiatra e psicanalista, é autor de inúmeros livros consagrados à imagem. Dentre eles, destacamos aquele em que se dedica a uma crítica de A câmara clara, Le mystère de la chambre claire: photographie et inconscient, apontando três pontos em que o texto barthesiano fracassa sem, no entanto, deixar de ressaltar o quanto Barthes fez pela fotografia.

As ideias do autor parecem mais claras e diretas na parte final do livro intitulado Conclusion, em que coloca a fotografia muito mais próxima da ideia de traço [trace] do que de rastro (pegada) [empreintre], pois esta é a marca deixada em profundidade por um corpo pelo contato com uma superfície, enquanto o traço, é menos o resultado do contato do que de uma ação física ou química. Para Tisseron (1996) pouco importa discutir se o signo fotográfico é mais índice do que ícone. Pouco importa o estatuto semiótico desse signo. Ele está interessado no efeito das relações que estabelecemos com a fotografia tanto como consumidores quanto espectadores. Desta maneira, Tisseron (1996, p.158) nota que: "Ela [a fotografia] não é a exaltação da morte até a representação da vida [...] mas ao contrário, a exaltação da vida até a representação da morte.”

Ao apresentar a fotografia como algo que cativa subjetivamente o espectador, e de engajá-la do lado de um pensamento mórbido, o autor parece deduzir que a imagem vincularia o seu espectador, sob uma forma atenuada, como a dor de um traumatismo que condenaria o sujeito a um eterno sofrimento (punctum). Tal fato, na visão de Tisseron, não 
corresponde ao que ensina os casos clínicos, visto que o psiquismo não rememora passivamente os traumatismos do passado, mas espera que o tempo trabalhe atenuando progressivamente o sofrimento. Sinaliza ainda que o punctum não é necessariamente algo doloroso, pois “[...] o processo de simbolização nos mostrou que a experiência secreta cuja introspecção se tornou impossível, não é necessariamente dolorosa pode ter sua origem numa experiência feliz”. (TISSERON, 1996, p.161).

Sua segunda crítica se coloca sobre a posição barthesiana da fotografia que a situa como "o retorno do morto”, por se tratar de uma imagem constituída pelo espectro que advém do sujeito fotografado e também pelo espectador que descobrem o objeto fotografado como desaparecido para sempre. Nesse sentido, Barthes contribuiu para a construção de uma teoria da fotografia como a revelação de um processo melancólico. Para Barthes, essa melancolia da fotografia se deve ao seu caráter indicial, que a coloca no status de imagem sagrada - archeiropoético -, mágica, louca, alucinatória intimamente relacionada à morte. Enquanto do ponto de vista de Tisseron a fotografia está bem longe dessa ideia corrente de "retorno do morto", mas muito mais perto da tentativa de ultrapassar a ferida aberta da separação primitiva - separação da mãe - que marca o funcionamento psíquico de todo ser humano.

A terceira crítica recai na sentença barthesiana de que “a imagem é da qual estou excluído”, pois a fotografia é um conjunto de signos que fazem referências a um passado que se torna a nos espectadores inacessível. Entretanto, segundo Tisseron, a imagem só exclui aquele que resiste ao seu convite de entrar e se deixar guiar por ela, ou seja, a fotografia não é senão um esqueleto de signos para aqueles que se recusam a “[...] abandonar sua carne e de explorá-la [a fotografia] como um corpo”. (TISSERON, 1996, p.165).

Ainda no pensamento psicanalítico da fotografia, devemos situar o texto de François Soulages, professor na Université de Paris VIII - Institut Nacional d'Histoire d'Arte, intitulado Barthes \& la folie empreinte ou la foi, le scandale et la foi por ocasião do Colóquio intitulado: "Empreintes 
de RolandBarthes" organizado pelo INA - Institut Nacional del'Audiovisuel, em 13 de junho de 2008, na Universidade Sorbonne, em Paris.

Nesse texto, o autor se debruça sobre esse último livro de Barthes que ele considera transtornante [bouleversant]. De saída, declara que $A$ câmara clara é um livro sobre fotografia, mas também da relação de Barthes com sua mãe e os últimos dias dela antes de vir a falecer. Nas páginas desse livro está entregue ao leitor um problema tão vivo naquele momento na vida de Roland Barthes: como viver a morte daqueles que se ama? A fotografia, como sublinha François Soulages, é um rastro (índice) louco que em face ao seu escândalo - retorno brutal do analógico - evoca nossa fé. Portanto a fotografia nos congela num passado ao qual não se volta mais. Ela guarda em si mesma um elo essencial com o divino que permite - segundo a leitura barthesiana - uma abordagem de fé desse nó que o autor estabelece entre fotografia, sofrimento e amor. Na leitura de Soulages, Barthes toma a fotografia como um "espaço existência edipiano" onde ao filho é permitido de reencontrar sua mãe morta, de continuar a viver este amor e alcançar, talvez aí, o êxtase: satori / punctum.

No limite, A câmara clara é uma tentativa a todo custo do discurso barthesiano de apresentar ao leitor a dificuldade de apreender a essência do sujeito fotografado e da própria fotografia em si. Porém, diante desse êxtase fotográfico que Roland Barthes vivencia na Fotografia do Jardim de Inverno de sua mãe, com cinco anos de idade, podemos acreditar que certas fotografias provocam uma experiência de fé, de amor e de loucura que não é demonstrável, mas que separa aquele que a pratica daquele que não a vivenciou: imaginário escandaloso e louco que só a fé coloca. E é aí que se situa o sublime da fotografia. Nesse sentido, para Soulages, o signo fotográfico barthesiano, esse rastro extraordinário do quasesobrenatural, não pode ser compreendido por aquele que nunca amou. Embora as críticas, como nota Soulages, sejam inúmeras por algumas das teses barthesianas sobre a fotografia: “[...] [A câmara clara] permanece de um valor inestimável dado a gravidade e a força de algumas interrogações relativas ao rastro, à fotografia, à mãe, ao amor, e à morte, relações obrigatoriamente existenciais e edipianas.” (SOULAGES, 2009, p.206). 
Em outro texto desse colóquio sobre Roland Barthes, intitulado Incarnations de Roland Barthes, de François Gaillard, professor de Filosofia na Universidade de Paris VII, observamos que a fotografia seria para Barthes um objeto que se oferece a várias práticas nas quais se engaja o corpo, ou mesmo, vários corpos: o do fotógrafo, do espectador e o daquele que foi objeto da fotografia. Para esse autor, “corpo" é uma "palavra-maná" da obra barthesiana que "marca a presença espectral da fenomenologia em tudo o que Barthes escreveu de $O$ grau zero da escritura à A câmara clara”. (GAILLARD, 2009, p.123).

A semiótica do rastro apresenta uma perturbadora e instigante continuidade: o objeto e o sujeito da enunciação não estão claramente distintos. Em Le singulier a l'épreuve ${ }^{1}$ de François Wahl editor que trouxe à público uma das obras póstumas de Barthes, Incidentes, sublinha a admirável maneira pela qual Roland Barthes tomou a fotografia como uma técnica psicoquímica, o que alguns denominam de "rastro" [empreinte]. (ARROUYE, 1990). Nesse tipo de registro, a interpretação somente poderia ser esmagada, reduzida a um puro reconhecimento do "é isso". Dessa maneira, não queremos afirmar que Barthes ignorou as intervenções do homem sobre a fotografia (enquadramento, distância, luz, etc) mas, como afirma Jean Arrouye - professor na Universidade d'Aix-emProvence no texto Narrativité photographiques ou l'animadversion de Barthes (MORA, p.40), dedicado ao livro A câmara clara - o que parece é que todas essas intervenções pertencem ao plano da conotação, a um código cultural de representação que não muda fundamentalmente a natureza do espetáculo observado e representado pela fotografia. A característica particular da fotografia - no seu estado literal e em razão da sua natureza absolutamente analógica - é a de constituir uma mensagem sem código. É no nível da coisa percebida, do espetáculo mostrado - plano da denotação - que se constrói e se manifesta o sentido da fotografia e é nessa mesma instância que se apresenta sua capacidade de fazer história.

${ }^{1}$ Texto retirado do livro Roland Barthes et la photographie: le pire du signe. Paris: Contrejours, 1990. p.14. (Cahiers de la photographie. n. 25), editado por Gilles Mora. 
Essa semiótica ou semiologia do rastro está intimamente associada à semiologia segunda que Émile Benveniste delineia: sentir o formigamento da língua, perceber o quanto o sistema (paradigma) está inscrito no próprio corpo daquele que vive naquela língua.

Gabriel Bauret, fotógrafo que teve sua tese orientada por Roland Barthes, em seu texto L'esquisse d'une théorie a la denière aventure d'une pensée (MORA, 1990, p.7), nota que se em A mensagem fotográfica - texto que se inscreve no contexto de Elementos de semiologia e que deve ser lido na mesma perspectiva de Mitologias Roland Barthes visionava uma possível teoria da fotografia.

A câmara clara se situa à margem de toda essa busca, ao menos à primeira vista, pois a famosa e instigante distinção que ele opera entre punctum e studium poderia ser considerado uma teoria sutil da fotografia. No entanto, essa dicotomia não constitui a mais interessante das teorias a respeito dessa arte. Para Bauret, podemos “considerar [A câmara clara] o mais autobiográfico de Barthes, mas, talvez, também o mais filosófico”. (BAURET, 1990, p.12). O discurso construído por Barthes é bastante estranho à história, à técnica e a todas as teorias elaboradas até aquele momento; entretanto, não deixa de se ser um dos mais pertinentes e instigantes olhares sobre a fotografia: "o olhar barthesiano é de uma lucidez que ele mesmo se assusta”, afirma Bauret (1990, p.13). Barthes refuta a teoria, como também a fotografia artística, para se dedicar a uma imagem particular, singular, íntima - a fotografia Jardim de Inverno - e colocar em causa sua forte presença evidente e sua circulação no seio de uma cultura daimagem.

Daniel Bougnoux - filósofo e professor emérito da Universidade de Stendhal de Grenoble - III -, em seu texto de abertura do colóquio "Les empreintes de Roland Barthes”, intitulado Les empreintes, non l'emprise, nota que desde 1968, com o texto $O$ efeito de real, bem como com a fotografia, a música e mesmo com certa poesia (haikai), Barthes inicia sua exploração de uma semiótica inferior - a do índice - que privilegia um signo não codificado, na fronteira entre a presença real e a representação. Para Bougnoux, o punctum fotográfico barthesiano e a aura benjaminiana 
são brechas filosóficas e semióticas para ir mais próximo do real: menos influência, mais presença no mundo, e mais distância. O caminho é dissociar o real de realidade. Nesse sentido, os trabalhos de Roland Barthes e Rosalind Krauss foram, talvez, os únicos a colocar a fotografia num justo ponto de vista: o da relação com o real. Segundo Jacque-Alain Miller, Lacan distinguiu a realidade de tudo o que existe, o real. A realidade seria tudo que seja perceptível, acessível, entendível pelo ser humano, enquanto o real seria o conjunto das coisas, independente de que sejam percebidos pelos seres humanos. Refere-se ao que é autêntico; inalterável verdade simultaneamente, um ser e a dimensão externa da experiência. É o que a linguagem (simbólico) não pode e não consegue tocar - o impossível -, impenetrável pelo sujeito para quem a realidade tem uma natureza fantasmática.

Diante das várias maneiras de denominar esse apagamento da linguagem: o punctum (êxtase fotográfico), o haikai ou até mesmo a efervescência amorosa. O sujeito experimenta “[...] um engajamento face ao objeto num indivisível, numa irrefutável imanência que é a sentença de morte do ego transcendental”. (BOUGNOUX, 2009, p.5). Há aí o desejo de possuir e ao mesmo tempo ser possuído: um jogo linguístico em que o discurso ou o sentido não pega. A sensação do punctum fotográfico não constitui a experiência de um sujeito em face a uma imagem, mas de uma sensação recebida do mundo a partir de uma invasão de um transe discreto que o deixa "cerrado-possuído-paralisado" [poigné-saisi-transi]. Enfim, nota ainda o autor que o punctum é a inversão do possuir, é o desprendimento [(dé) saisissement] do sujeito sensível, e o apagamento do studium, ou melhor, de qualquer tentativa e desejo de empreendimento retórico.

Nesse sentido, para Bougnoux, o rastro do punctum parece se deslocar do sentido da visão para o tátil. Esse deslocamento não quer dizer muito, a não ser um maior arrebatamento do sujeito. Essas impressões e rastros não são senão maneiras discursivas de colocar em evidência o "não-querer-possuir" que leva a uma atenuação da arrogância e da inevitável violência de nossas várias enunciações. Estamos cada vez mais 
próximos do desejo de Neutro. "Não-querer-possuir”, como pensa Eric Marty - editor das Oeuvres complèts de Roland Barthes e professor de literatura na Universidade de Paris VII, em seu livro Roland Barthes: o ofício de escrever - é essa queda fora da linguagem que, por sua vez, estaria próximo do sentido de neutro que em uma das suas acepções poderia ser entendido como a falta de linguagem, uma forma de silêncio, de apagamento, de suspensão do sujeito. O “não-querer-possuir” é o êxtase eternamente suspenso em um puro presente.

O texto Du signe à la trace, de Louise Merzeau - conferencista em ciências da informação e da comunicação e membro do laboratório CRIS - Centre de Recherche em information spécialisée et médiation des savoirs, desse mesmo colóquio em homenagem a Barthes - aponta que os rastros, para esse autor, podem assumir várias formas e ter vários nomes, segundo o contexto e o objeto evocado: satori, picada, detalhe, punctum, dentre outros. São termos que não podem ser teorizados, pois deslocam o texto crítico do campo teórico para conduzi-lo mais próximo de uma escritura-traço. Como sublinha Merzeau (2009, p.127), o texto- traço é “descrito como um corpo marcado de afetos”. A obra barthesiana é marcada por essa escritura sintomática em que o discurso perde a arrogância da certeza de tudo saber. Para Merzeau, é na fotografia que o texto-traço volta próximo de seu modelo e sua lógica: “ela [fotografia] reconstrói a mesma lógica indicial que separa o discurso de sua interpretação”. (MERZEAU, 2009, p.131).

Como se pode observar, nesses últimos escritos sobre fotografia, Barthes não a encara mais como signo analógico, mas como um traço, uma emanação luminosa, uma parte do corpo ou uma pele. Merzeau sublinha que Barthes lida com o que há de mais evidente em matéria de sentido na fotografia: "na fotografia, eu não posso jamais negar que a coisa esteve lá”. (MERZEAU, 2009, p.131) Para esse autor, não podemos encarar A câmara clara como uma semiótica. Barthes parece se entregar ali uma coalescência do signo, para produzir um discurso fenomenológico que não cede a analogia do signo, fazendo desse livro 
não uma questão específica de índice, mas de um traço do “isso existiu” [ça-a-été].

Daniel Bougnoux sinaliza um importante passo no horizonte da escritura de A câmara clara: aquele ligado ao fato de o livro ter servido como forma de investigação num campo de pesquisa que ele denomina “mediologia”, campo teórico que traz a lume os efeitos simbólicos das inovações tecnológicas. Assim, separando conteúdo da forma, a maneira de analisar a imagem fotográfica introduzido pelo rastro, tal qual empregada por Barthes, não tem nenhuma relação com a mensagem, mas com o meio e com a forma. É o que justifica a substituição “[...] da economia da mensagem por uma economia do media e a semiologia por uma mediologia”. (BOUGNOUX, 2009, p.141).

\section{O olhar barthesiano sobre a fotografia}

Todos os comentadores de A câmara clara sublinham essa busca fenomenológica pela essência da fotografia - saber a todo custo o que ela em si mesma - que passa, por sua vez, pela insistência barthesiana no aspecto material e químico da fotografia, pois ela é a prova “é isso" [c'est ça] de que "isso existiu” [ça-a-été].

Este é o noema da fotografia, ou seja, aquilo que é percebido, apreendido do objeto da percepção. A fotografia é apreendida por Barthes como fenômeno de consciência: é a coisa em sua essência que importa. É na fotografia do jardim de inverno que o autor, então, reencontrou sua mãe - sua realidade, seu passado - porque ela (a fotografia) é uma emanação do referente, um rastro, um traço dela.

O efeito que esse traço, essa emanação produz não é o de restituir o que foi abolido pelo tempo, pela distância, mas um atestado de que o que vejo existiu ou aconteceu. A fotografia é o testemunho de fé que atesta a ressurreição e proclama essa boa nova. Tal é esta demonstração e este testemunho nela encontrado que leva Barthes a compará-la ao santo sudário. 
A questão que fica é: como lidar com essa virada teórico-conceitual instaurada pelo punctum no campo das imagens? Podemos de saída dizer que não tem nada a ver, por exemplo, com a concepção de “memória involuntária” tão cara à obra proustiana, Em busca do tempo perdido.

Para o último Barthes de A câmara clara, não há nada de memória na fotografia pungente, o que ela provoca é um atestado de que aquilo que se registrou sobre a chapa metálica realmente aconteceu, “estava lá”. De resto basta saber o quanto Barthes se refere a Proust e o quanto Proust está presente em seus momentos finais, sendo um tema recorrente nas derradeiras aulas no Collège de France. Talvez o que induz os comentadores de A câmara clara a pensar que o punctum é o que há de mais proustiano nesse Barthes, apontando apressada e erroneamente que Barthes se contradiz, pois, no fragmento 28 ele afirma:

Por uma vez, a fotografia me dava um sentimento tão seguro quanto a lembrança, tal como a experimentou Proust, quando, ao abaixar-se certo dia para descalçar-se, percebeu bruscamente em sua memória a face de sua avó verdadeira, 'cuja realidade viva pela primeira vez eu encontrava em uma lembrança involuntária e completa’. (OCV, 2002, p.845).

Já no fragmento 35, logo na abertura, o autor expõe: "A fotografia não rememora o passado (não há nada de proustiano em uma fotografia)." (OC,V, 2002, p.855). Esclareçamos o fato. Barthes não afirma que a fotografia tem algo de (re) memória proustiana; ele simplesmente compara a memória involuntária proustiana ao registro fotográfico para que se faça notar o paradoxo entre um e outro. A fotografia para Barthes é a restituição/ressurreição, enquanto a memória involuntária em Proust é um lance de embriaguez dos sentidos que nasce das sensações, do afeto que pode, ao mesmo tempo, restituir ou encobrir experiências passadas.

Contudo, os leitores de Em busca do tempo perdido sabem o quanto esses flashes de memória são postos em dúvida pelo narrador, o que o impede de se entregar completamente ao que revela o depoimento 
de suas próprias sensações. Assim, essa aparente contradição barthesiana se desfaz quando novamente Barthes recorre a Proust para negá-lo ("não há nada de proustiano em uma foto”), pois em A câmara clara, a fotografia não rememora nada, e sim restitui, faz emergir num "presente louco”, algo que não existe mais, mas que ao mesmo tempo sua essência está lá impregnada nos sais de prata da película fotográfica.

Assim, a boa fotografia simplesmente coloca diante do olhar do Spectator um passado (ça a été), um presente (o sujeito fotografado é lá em forma de spectum) mas, ao mesmo tempo, anuncia uma verdade, ( $c^{\prime}$ est ça) e um futuro (a eminência da morte).

A fotografia está antropologicamente ligada à morte pelo seu poder de imobilizar o tempo e a interpretação, o que faz que aquele evento registrado se perpetue num movimento de eterno retorno, excluindo qualquer possibilidade de catarse. É esta visão filosófica grave a respeito da fotografia que leva Barthes a afirmar, bem na abertura do fragmento 38:

Todos esses jovens fotógrafos que se movimentam no mundo, dedicando-se à captura da atualidade, não sabem que são agentes da Morte. É o modo como nosso tempo assume a Morte: sob o álibi denegador do perdidamente vivo, de que o Fotógrafo é de algum modo o profissional. (OC,V, 2002, p.865).

O estatuto semiótico da fotografia se situa além da forma estabelecida pela representação: a fotografia nos coloca diante de uma individualidade sem código, sem máscara, até mesmo sem mediação. A verdadeira ferida da fotografia está no seu curto-circuito temporal: tornar o passado presente. No entanto, esse passado é agora presente como morto. O que parece é que a fotografia consolida o sonho barthesiano de escritura branca, estatuto que a linguagem só pode sonhar em tangenciar. A neutralidade do signo constitui a característica essencial desse regime de representação. Porém essa neutralidade na essência da fotografia parece ser abafada, fazendo-nos esquecer de que se trata de uma analogia do retorno brutal para se passar como uma analogia do efeito natural (arte). 


\section{Referências}

ARROUYE, Jean. Narrativité photographiques ou l'animadversion de Barthes. In: MORA Gilles (Ed.). Roland Barthes et la photographie: le pire du signe. Paris: Contrejours, 1990. (Cahiers de la photographie. n. 25).

BARTHES, Roland. Oeuvres complètes 5T. 9. ed. Paris: Seuil, 2002.

. O neutro. São Paulo: Martins Fontes, 2003.

BATCHEN, Geoffrey. A câmara clara: outra pequena história da Fotografia. Revista Comunicação \& Linguagem, Lisboa, n. 39, p.13-26, jun.2008.

BAURET, Gabriel. L'esquisse d'une théorie a la denière aventure d'une pensée. In: MORA Gilles (Ed.). Roland Barthes et la photographie: le pire du signe. Paris: Contrejours, 1990. (Cahiers de la photographie. n.25).

BENJAMIN, Walter. Obras escolhidas: magia e técnica, arte e política. São Paulo: Brasiliense, 1994.

BENVENISTE, Émile. Problemas de linguística geral II. Campinas: Pontes, 1989.

BLANCHOT, Mauricie. O livro por vir. São Paulo: Martins Fontes, 2005.

BOUGNOUX, Daniel. Les empreintes, non l'emprise. In:

(Org.). Empreintes de Roland Barthes: actes du colloque organisé par l'INA sous la direction de Daniel Bougnoux. Nantes : C. Defaut : INA, 2009. p.11-22. 
CESAROTTO, Oscar. No olho do outro: o homem de areia segundo Hoffman, Freud e Gaiman. São Paulo: Iluminuras, 1996.

DUBOIS, Philippe. O ato fotográfico. Campinas: Papirus, 1994.

FRADE, Pedro Miguel. Figuras do espanto: a fotografia antes da sua cultura. Coimbra: ASA, 1998.

GAILLARD, François. Incarnations de Roland Barthes. In: BOUGNOUX, Daniel (Org.). Empreintes de Roland Barthes: actes du colloque organisé par l'INA sous la direction de Daniel Bougnoux. Nantes : C. Defaut : INA, 2009. p.109-124.

KRAUSS, Rosalind. Le photographique. Paris: Macula, 1992.

MARTY, Éric. Roland Barthes: o ofício de escrever. São Paulo: Bertrand Brasil, 2009.

MEDEIROS, Margarida. A fotografia, a modernidade e seu segredo: antes e depois de Barthes. Revista Comunicação \& Linguagem, Lisboa, n. 39, p.27-46, jun. 2008.

MERZEAU, Louise. Du signe à la trace. In: BOUGNOUX, Daniel (Org.). Empreintes de Roland Barthes: actes du colloque organisé par l'INA sous la direction de Daniel Bougnoux. Nantes: C. Defaut : INA, 2009. p.125-146.

MILLER, Jacque-Alain. Percurso de Lacan: uma introdução. Rio de Janeiro: Jorge Zahar, 1987.

MILNER, Jean-Claude. Le pas philosophique de Roland Barthes. Paris: Verdier, 2003. 
MORA Gilles (Ed.). Roland Barthes et la photographie: le pire du signe. Paris: Contrejours, 1990. (Cahiers de la photographie. n. 25).

SAMAIN, Etienne. Um retorno à Câmara Clara e a antropologia visual. In: (Org.). O fotográfico. São Paulo: Hucitec, 1998. p.115-128.

SOULAGES, François. Barthes \& la folie empreinte ou la foi , le scandale et la foi. In: BOUGNOUX, Daniel (Org.). Empreintes de Roland Barthes: actes du colloque organisé par l'INA sous la direction de Daniel Bougnoux. Nantes: C. Defaut : INA, 2009. p.203-222.

TISSERION, Serge. Le mystère de la chambre claire. Paris: Flammarion, 1999.

WAHL, François. Le singulier a l'épreuve. In: MORA Gilles (Ed.). Roland Barthes et la photographie: le pire du signe. Paris: Contrejours, 1990. (Cahiers de la photographie. n. 25). 